\title{
Morpheus: A Platform for the Representation, Manipulation and Secure Access of Standardized Morphological Data for the Digital Age Textile Industry
}

\author{
Julien DUCRET ${ }^{* 1}$, Cédric CLAIRE ${ }^{1}$, Alexis CHARLOT ${ }^{1,2}$, Xavier AMEZIANE$^{1}$, Samuel CRUZ-LARA ${ }^{2}$ \\ ${ }^{1}$ Morpheus SAS, Nancy, France; \\ ${ }^{2}$ LORIA UMR 7503 - University of Lorraine, Vandœuvre-lès-Nancy, France
}

https://doi.org/10.15221/20.08

\begin{abstract}
This document presents Morpheus: a platform for the representation, manipulation and secure access of standardized morphological data for the digital age textile industry.
\end{abstract}

Keywords: Digital transformation of the custom-made clothing industry, standardized morphological data, blockchained morphological passport, 3D human body data, personal information manager system

\section{Introduction}

Faced with the challenges of industry X.0: mass production of unique pieces, obtaining customer data is becoming a major issue for the on-demand and personalized manufacturing of all types of products. In addition, the creation of large and qualified volumes of data is essential for the emergence of new Al services for our digital age industry. Finally, the burning news prompts us to put the confidentiality of our personal data at the center of our concerns. Faced with these observations, the creation of a platform dedicated to morphological data seems particularly appropriate in the field of the clothing and personal equipment industry, online distribution, tailor-made and luxury. Such data are also of particular interest in the field of health and sport.

Within this inevitable digital transformation of the textile industry where the transmission of personal data is a major issue, today there is no complete standard, bridge or pivotal language, related to morphological data.

This is why we are creating a platform for the representation, manipulation and secure access of standardized morphological data for the digital age textile industry: Morpheus (see figure 1).

Morpheus will provide people with personal data protection, interoperability and even monetization of information mainly associated with body measurements.

Morpheus aims at creating a "blockchained morphological passport" for allowing the interoperability of personal data with all services related to the custom-made clothing industry and is participating to the rise of new economic models based on the use of this data.

Blockchain technology will allow to record transactions between two parties efficiently and in a verifiable and permanent way. Morpheus also contributes to the emancipation of individuals who will decide on the use of their own personal data: set up, update, deletion, monetization.

A crucial point of Morpheus' work is to ensure the right to data portability for all as specified in the European Union's GDPR law. 


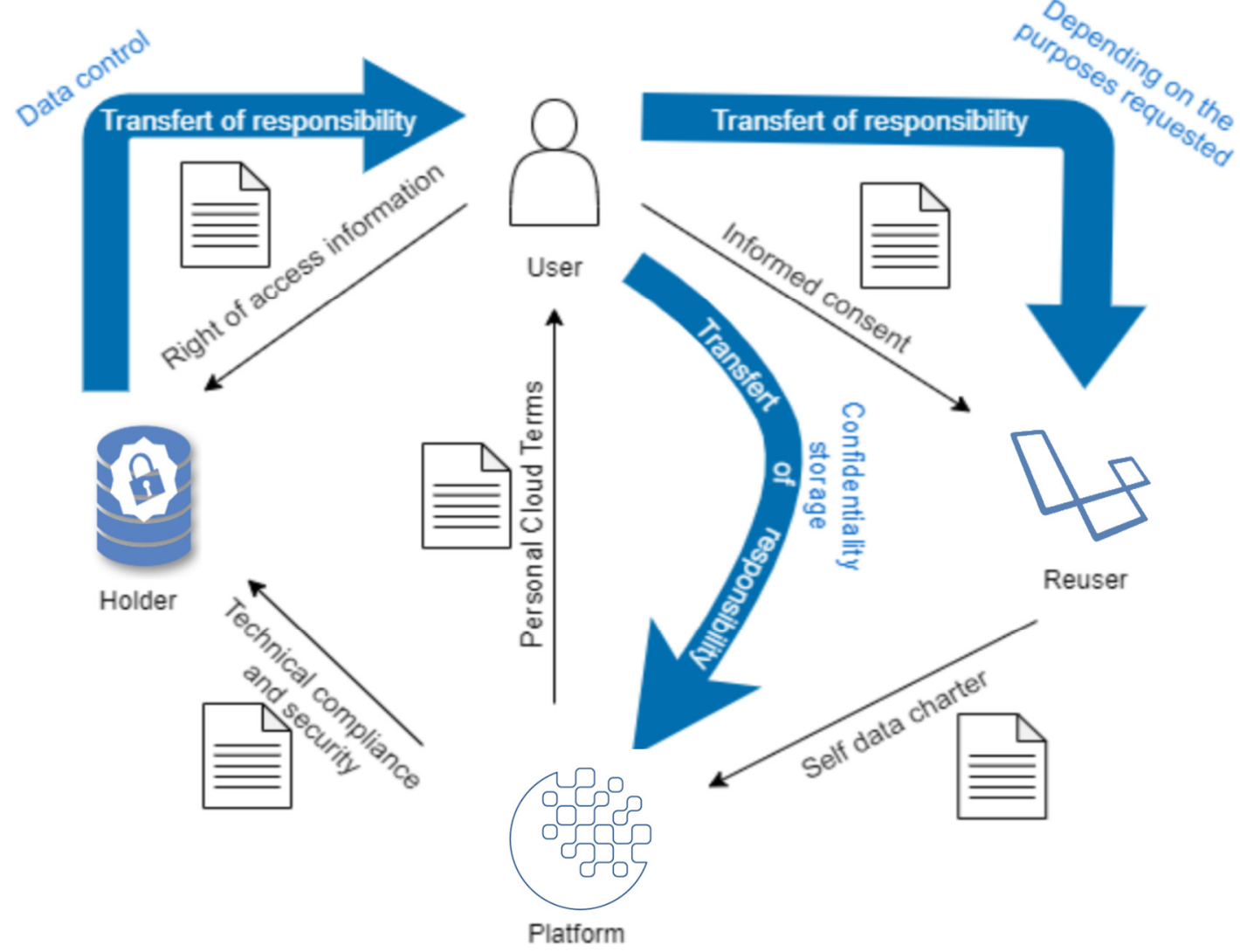

Fig. 1. The Morpheus project

The quality of morphological data is also at the center of our platform. We thus guarantee a high level of interoperability, security and relevance of this data. We will follow and contribute to the evolution and monitoring of standards, evaluation and security of services. The platform, in addition to ensuring the maintenance and history of user's profiles, must also offer a bridge between all different players and provide the best solutions.

Morpheus aims also at implementing a real Green Economy project allowing a concrete reduction of logistics and production circuits.

The main objectives of the project are:

1. Transformation of morphological data into a standardized and unique digital format.

2. Allow individuals to manage their own personal data in accordance with the PIMS model.

3. Provide a massive and anonymized data warehouse for the emergence of new uses.

4. Develop tools for interfacing the standardized morphological passport to the available measurement tools.

\section{Morphological data}

If the manual measurement can be easily described in paper or stored in a computer record, it is not the same for the many data from voluminous 3D scan and their analysis. More generally, regarding the acquisition of morphological data, there are as many data formats as there are machines available on the market. Soon, new forms of measurement will appear (Smartphone, 2D image analysis ...) and always with their own ways of representing and manipulating their data. In the absence of a real standard, the interoperable use of morphological data will be impossible or will be greatly reduced. However, the use of a standard is not intended to change the output formats of the different tools. It will be necessary to provide for a transformation, as automatic as possible, from any format to the pivot language defined by the standard. 


\subsection{Where do they come from?}

\subsection{1. $3 D$ booths}

Currently, there are more than a dozen different 3D booths with an ecosystem that is struggling to impose itself and to find its business model. We first worked on export files of "bodyscan", a software application from the Telmat company [1,2].

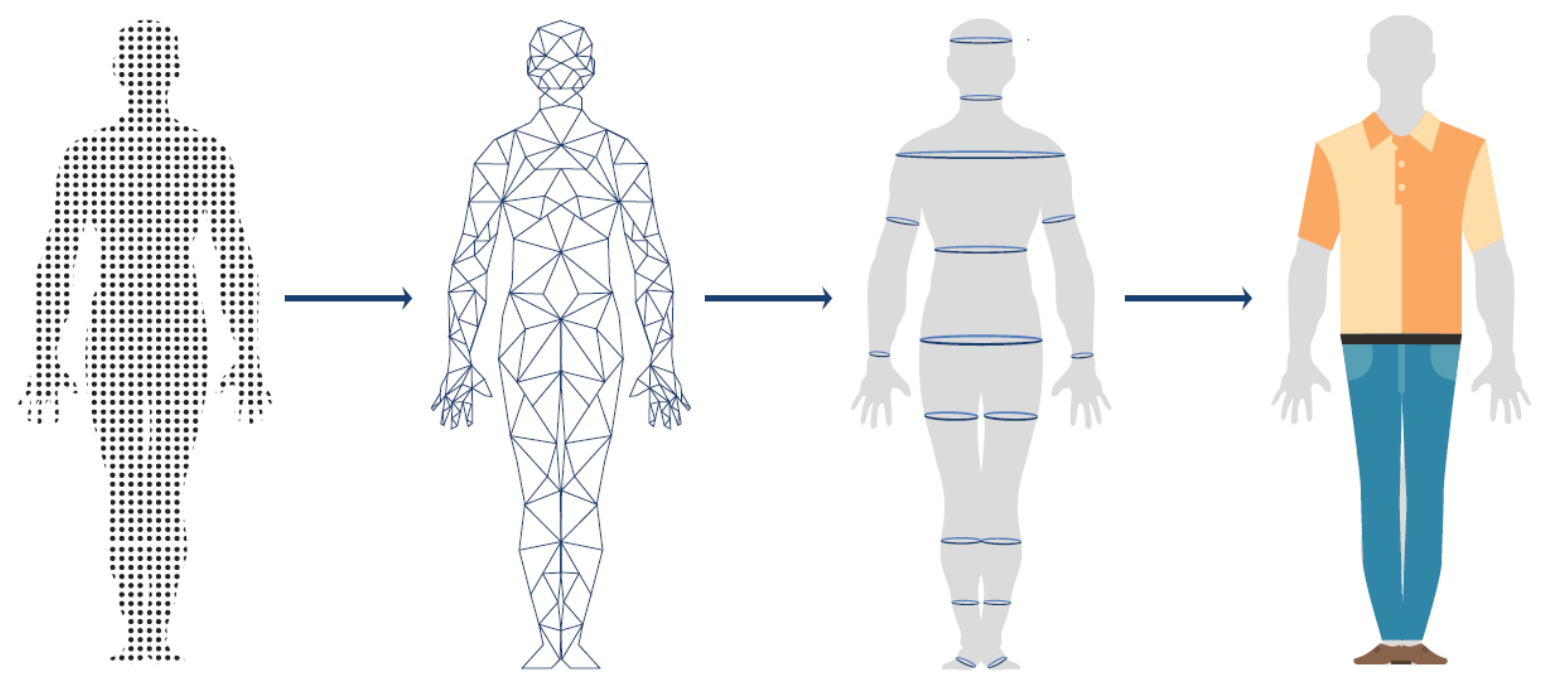

Fig. 2. From bodyscan to usage, the missing 2 steps: vectorization and standardization of data

The creation of morphological data files (see Figure 2) is done first by analyzing multipoint (very heavy process) or vectorized (less heavy process) bodyscan. Vectorization allows the reduction of the file size but also a first "cleaning" on data for a more faithful rendering. At this level we recommend the use of a standard easily exchangeable on the web [3].

Very few solutions exist to extract morphological data from the bodyscan for building small easily exchangeable files. This is why we are campaigning for the constitution of numerous vectorized bodyscan libraries in order to develop measurement extraction solutions by learning. We can also note the acquisition by Amazon of the specialized startup BodyLabs in October 2017, which makes this technology the keystone of tomorrow's online sales.

\subsubsection{Digital tools}

It is very difficult to have an exhaustive view of the digital tools for acquiring existing morphological data as the offer is large and comes from the same business model: capture part of the costs of clothing returns due to a problem of cut. Hence a preponderance in the creation of morphological passports in silos for the recommendation of clothing size [4].

\subsubsection{Morpheus morphological blockchained passport}

Even if projects to acquire $1 \%$ of the exorbitant cost of returns in e-commerce are easily fundable with investors, the fact remains that the acquisition of $1 \%$ of the population is impossible alone and leads to the Most startups filing for bankruptcy. We need to think about a global acquisition of morphological data including the fair remuneration of all actors: individuals, measurement tools, passport management.

Without individuals motivated by the imperative need to preserve our planet, without a certain profitability of quality morphological data acquisition tools and without a good performance of the pruning recommendation systems, we will not obtain an in-depth modification of the economic model. current.

Block Chain technology, by its properties, provides us with an essential solution to the sector's profitability problem. When each transaction on the morphological passport (creation, reading, modification) can be recorded in an unalterable register thus bringing the authorship of the creation of the data (purchase of a product, measurement of an individual), the knowledge of the actors who have access to them or even what system maintains or logs them. Interactions with the system can also be monetized via a user token and thus finance the creation of the morphological passport: remunerate the provision of data by charging those who consume it. 
It should be noted that in the morphological passport currently developed by MORPHEUS, during the computer transaction between the user and a recommendation, only the necessary data is transmitted. For example, when a customer chooses a sweater, the data exchanged relates only to the upper body. This reduces the dissemination of personal data while ensuring quality of service.

\subsubsection{The tools of tomorrow}

The tools of tomorrow are already here! From 2010 to 2019, more than 500 publications of the "3D body tech conference" link different technologies for digitizing and processing 3D body models to several categories [5] (see figure 3).

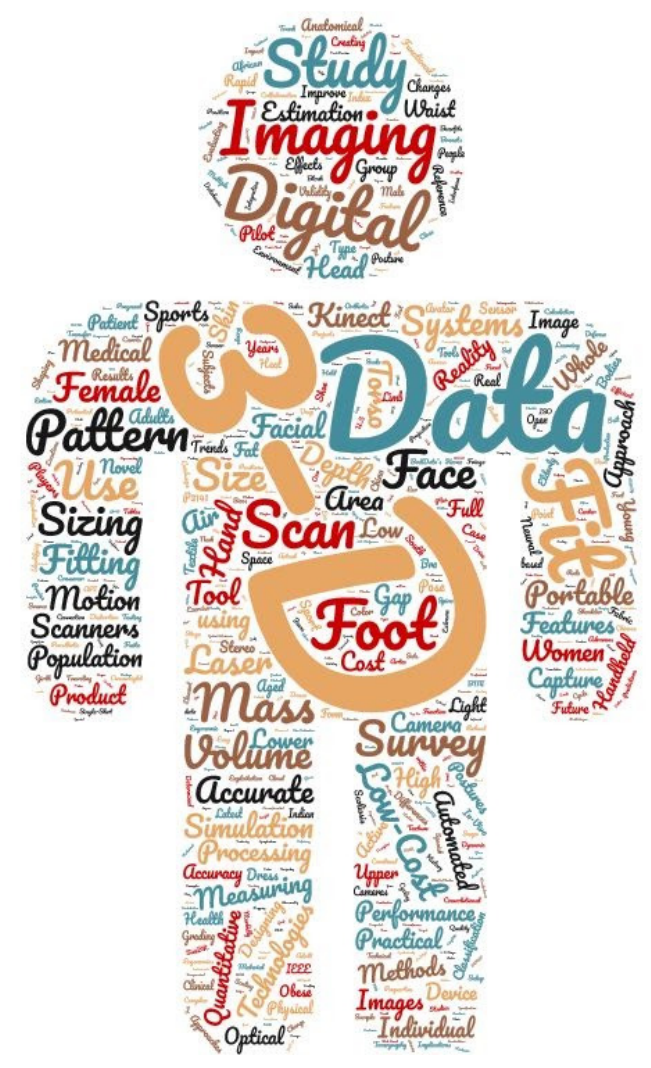

Fig. 3. Word cloud of full papers from 2010 to 2019 - 3DBODY.TECH 2019 (by Morpheus).

\subsection{Current standard}

Here too, the field of possibilities is quite vast and goes far beyond the sacrosanct market of size recommendations for the textile industry. It should be noted that the different uses of morphological data also use their own formats: Excel file, XML, forms, etc. As for the generation of morphological data, the standard does not impose a format on the tools but offers useful reading for each use.

\subsubsection{ISO 8559-1}

The ISO 85558-1 standard defines a terminology for the main measurement points for the textile industry. However, it is not exhaustive and does not list certain measurement points produced by the recent bodyscan analyzer [6].

\subsubsection{IEEE P3141}

This standard addresses the fundamental attributes that contribute to 3D body processing quality of experiences, as well as identifying and analyzing existing metrics and other useful information relating to these attributes. It defines a standardized suite of objective and subjective methods, tools and frameworks for assessing 3D body processing quality of experience attributes, and it specifies methods, tools and frameworks to facilitate standards-based interoperability, communication, security and comparison among 3D body processing technologies such as 3D/depth sensors, scanners, digitization, simulation and modeling, analytics and animation/visualization for solution providers as well as for consumer facing companies such as in retail, health/wellness, sports/athletics, medical industries $[7,8]$. 


\subsubsection{EN 13402 Size designation of clothes}

EN 13402 Size designation of clothes is a European standard for labelling clothes sizes. It is based on body dimensions, measured in centimeters (see figure 4). It replaces many older national dress-size systems in popular use before the year 2007. Acceptance of this form of standardization varies from country to country.

13 measurement points from standard ISO 85558-1 (EN 13402-1) are thus correlated with types of clothing (EN 13402-2) via the selection of a primary measurement and one or more secondary measurements necessary for the correct description of the garment. The representation of these measurement points or intervals (EN 13402-3) is done via an explicit pictogram but too complex for human analysis. The definition of digital coding for automatic processing by (EN 13402-4) has been abandoned.

\subsubsection{ISO TC37/SC4}

This normative ISO committee deals with the Standardization of descriptions, resources, technologies and services relating to terminology, translation, interpretation and other language-related activities in the multilingual information society.

Naming a garment with the appropriate term is not trivial because the variants chosen usually specify a way of wearing the garment (baggy, slim, regular) or else determine a part of the body that is hidden or uncovered (turtleneck, round or V). Very often there is something cultural about naming in different ways a garment which covers the same part of the body or which discovers another. Standardized multilingual terminology for fitting and clothing would allow better communication in natural language with clothing research and recommendation tools.

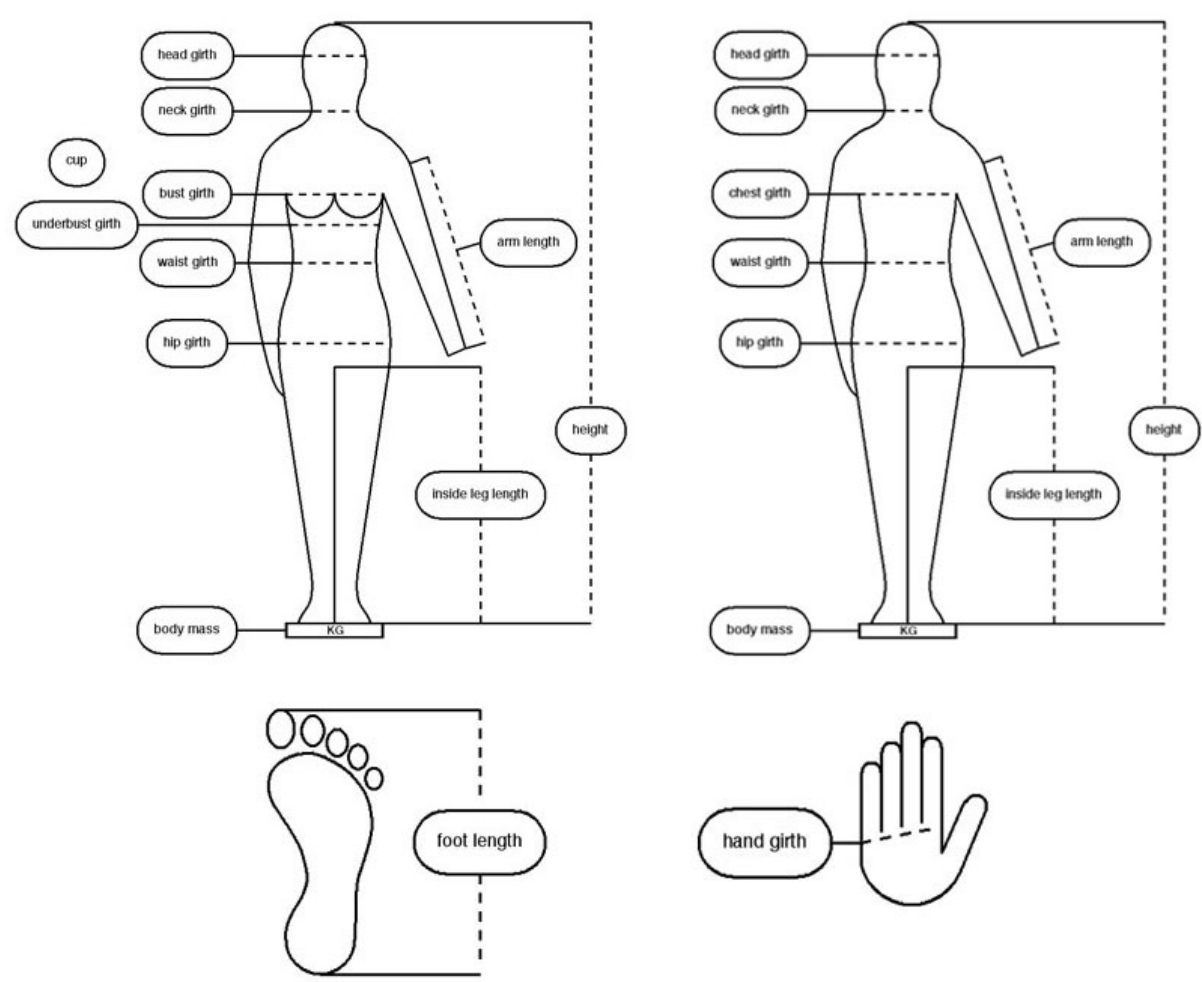

Fig. 4. Pictogram and different measurement points of standard EN 13402

\section{The size recommendation}

The size recommendation in ready-to-wear can be seen on the consumer side but also on the business side. The recommendation is a process of matching between a garment and an individual according to personal preferences but also between a production of clothing and a population [9]. It would allow savings on return costs estimated at $£ 20$ billion according to the eponymous white paper of Fit-me [10]. 
Alternative methods:

\section{Obtaining by algorithm}

This method is largely the result of measurement campaigns and will continue to improve with the constitution of massive databases. Note however that the only database available for France dates from 2003. It is the property of the French Institute of Textile and Clothing (IFTH). Note also the poor accuracy of the size recommendation on the profiles that go out of the normal.

\section{Obtaining by deduction - homology}

Tell me what you wear I'll tell you how you are. Or again: my neighbor has the same weight, the same height and the same age as me, there is a good chance that what suits her will also suit me... or not! In this case, it is the clothing data that must be assembled in order to deduce the morphology of the consumer. Then you will say that we impose things on you!

The main difficulty of the different size recommendation services and tools is to recover this data, brand by brand. In addition, this establishes a very strong dependency link between the brand and the recommendation tool. All the players thus work on closed, proprietary and non-interoperable technologies.

When we wanted to enter the size guides by brand, we found that each one uses a different formalism. We would have liked to see the European standard EN 13402 developed more widely and even more so with section 4, which could have automated the acquisition of clothing data. Because, for the same garment, the classification system is different. (put a real example of Brand $X$ which details the elements of a shirt and Brand $Y$ which mixes shirt, sweater, dress and jacket in one guide). This requires considerable manual re-entry work to harmonize all this data in a single repository. Some brands do not publish their size guides because they consider it a trade secret. These constraints make it impossible to set up an automatic system for the online store, for example.

\section{Challenges}

\subsection{Right to portability}

After having tested most of the major recommendation tools on merchant sites, there is a heterogeneity of the processes (algorithm, homology, measurement) for obtaining consumers' personal data. Thus, for each tool, the user must not only create a specific account, enter and re-enter their data without being able to export them and use them again in another tool. It is important for the user to share an explicit but ephemeral consent of his morphological data. The user can exercise their right to erase their data by revoking this sharing at any time.

The right to portability of personal data, Article $20 \S 1$ of the GDPR (p45) [11] requires that data be transmitted "in a structured, commonly used and machine-readable format". This implies the interoperability of data processing, and the generalization of one or more "standard" formats. Hence the importance of the emergence of such a format!

\subsection{Data quality and Al}

The use of morphological data, size recommendations, tailor-made, statistics and Al (artificial intelligence), are struggling to emerge due to a lack of available and quality customer data. However, 3D measuring machines are ready, but not profitable at present due to lack of opportunities. MORPHEUS reconciles the expectations of people concerned with the security and confidentiality of their personal data with the needs of the textile industry which must meet the challenges of tomorrow: on-demand, just-in-time, shopping experience, customer satisfaction, after-sales service, corporate social responsibility.

The morphological data are by nature extremely changing according to the weight gain of the human body. Hence the importance of regularly updating your personal data if we want to guarantee quality recommendations. Likewise, the historization of morphological data can be of significant interest to the health of the individuals observed. Depending on the platform, we can thus determine the historical limits on the border between fashion and health. 
The Villani report [12], "making sense of artificial intelligence", indicates that "first, an offensive policy aimed at promoting access to, circulation of and sharing of data. Data is the raw material of contemporary $\mathrm{Al}$ and on it depends the emergence of many uses and applications "in its economic policy strategy.

Our role here is to bring out a massive amount of morphological data necessary for the development of artificial intelligence for the recommendation of personal equipment for the X.0 industry while reducing its ecological impact. For this it is also necessary to aggregate in the passport other related data such as the morphological typology of people (see figure 5), fitting preferences (loose, fitted), sartorial tastes (colors, materials), fitting and shopping experiences [13].

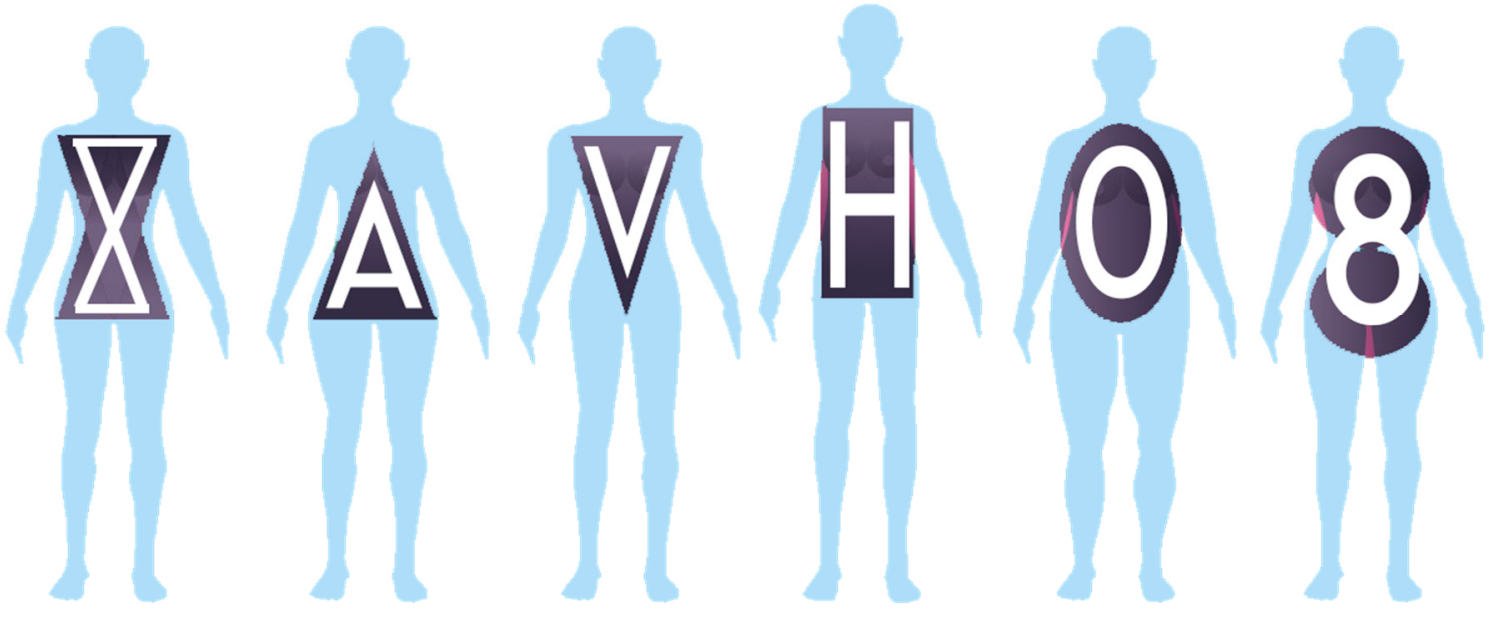

Fig. 5. The different human morphotypes.

\section{The solution}

\subsection{System interoperability}

The first real challenge for Morpheus is the creation of a computer language for the exchange of morphological data. For this, a consortium with the University of Lorraine was created and funded by the Grand-Est region in order to define a standardized digital format for human morphologies as well as clothing data: a universal representation standard for morphological data. This need for standardization has been demonstrated in numerous studies carried out by LORIA (Lorraine Research Laboratory in Computer Science and its Applications - UMR 7503) and the SYNALP (SYmbolic and statistical NAtural Language Processing) team. [14,15].

\subsection{Data confidentiality}

As the user is legitimately concerned about the confidentiality of his personal data, we recommend the use of a system that aggregates and securely stores his standardized morphological data in the form of an individual digital passport, anonymized and interoperable with all current and future uses. The architecture should be compatible with the PIMS standard [16] in order to ensure the explicit sharing of personal data and revoke it automatically and at any time if the passport owner requests it.

\subsection{Inclusive vision}

The textile industry is the second most polluting human activity and this sector contributes significantly to global greenhouse gas emissions with 1.7 billion tons of $\mathrm{CO} 2$ per year [17]. If the observation is shared, it is nonetheless addressed in an individual and scattered manner. The constitution of big data (vast databases centered on customer knowledge) is the essential condition for the emergence of the X. 0 industry and the change in the economic model of our industries.

"When it's free, you're the product". 
A system for collecting personal data must consider all its users as economic and responsible actors. It gives them the opportunity to interact and gives meaning to their approach. By monetizing their personal data, the holder of the morphological passport will be able to promote actions useful for the planet through donations. They can also choose to share their data with their relatives or participate in scientific studies. Thanks to this inclusive vision of all stakeholders (consumers, distributors, producers) we will be able to significantly reduce the environmental impact of the textile industry, dear to a growing part of the population.

\section{Conclusion}

In this new value chain, the emergence of a standardized morphological passport will allow the interoperability of personal data with all current and future use services and will participate in the emergence of large databases conducive to $\mathrm{Al}$ and the acquisition of new knowledge. The passport must also comply with all the requirements of the RGPD in order to reassure its users when the future of their personal data.

The pursuit of global standardization of morphological data will also allow the establishment of a Green Economy project which will allow the reduction of logistics and production circuits. This crucial step can be taken at European level if industrialists and academics unite now around this imperative need to speak the same language. Following the example of the 3D Web Consortium [18] and The 3D Body Processing (3DBP) Industry Connections Working Group [19] we wish to open up to all our consortium formed with the University of Lorraine to go further in the development of standards for personal equipment: representation of morphological data, digital size guide, clothing terminology, tool interoperability, etc.

\section{References}

[1] Telmat Industrie. http://telmat-net.fr/

[2] Les 10 meilleurs scanners corporels 3D en 2020. https://www.aniwaa.fr/guide-achat/scanners$3 \mathrm{~d} /$ meilleurs-scanners-corporels-3d/

[3] A. Ballester et. al, "3D Human Models from 1D, 2D \& 3D Inputs: Reliability and Compatibility of Body Measurements", in Proceedings of 3DBody.Tech 2018, 9th Int. Conference and Exhibition on 3D Body Scanning and Processing Technologies, Lugano, Switzerland, 16-17 Oct. 2018.

[4] S. Xia et. al, "Acquiring Accurate Body Measurements on a Smartphone from Supplied Colored Garments for Online Apparel Purchasing Platforms and E-Retailers", in Proceedings of 3DBody.Tech 2018, 9th Int. Conference and Exhibition on 3D Body Scanning and Processing Technologies, Lugano, Switzerland, 16-17 Oct. 2018.

[5] 3DBody.Tech Conference. https://www.3dbody.tech/cap/home.html

[6] ISO 8559-1:2017. Size designation of clothes - Part 1: Anthropometric definitions for body measurement. https://www.iso.org/standard/61686.html

[7] IEEE SA Standards Association. https://standards.ieee.org/project/3141.html

[8] C. McDonald et. al, "Working Group Progress for IEEE P3141 - Standard for 3D Body Processing, 2017-2018, in Proceedings of 3DBody.Tech 2018, 9th Int. Conference and Exhibition on 3D Body Scanning and Processing Technologies, Lugano, Switzerland, 16-17 Oct. 2018.

[9] A. Rissiek and R. Trieb, "iSize - Implementation of International Anthropometric Survey Results for Worldwide Sizing and Fit Optimization in the Apparel Industry", in Proceedings of 3DBody.Tech 2010, 1st Int. Conference and Exhibition on 3D Body Scanning and Processing Technologies, Lugano, Switzerland, 19-20 Oct. 2010.

[10] Rakuten FitsMe, Imperfect fit and the £20 billion cost of returns, 2016. https://fits.me/wpcontent/uploads/2017/01/Whitepaper-Imperfect-Fit-and-20billion-Cost-of-Returns.pdf

[11]Règlement (UE) 2016/679 du Parlement Européen et du conseil du 27 avril 2016 relatif à la protection des personnes physiques à l'égard du traitement des données à caractère personnel et à la libre circulation de ces données, et abrogeant la directive 95/46/CE (RGPD Règlement Général sur la Protection des Données), pp 45, Journal officiel de l'Union Européenne 
[12] Donner un sens à l'intelligence artificielle pour une stratégie nationale et européenne, Cédric VILLANI, Mars 2018, ISBN 978-2-11-145708-9.

[13]E. Lapkovska et. al, "Garment Fit: Where Do We Stand?", in Proceedings of 3DBody.Tech 2010, 10th Int. Conference and Exhibition on 3D Body Scanning and Processing Technologies, Lugano, Switzerland, 22-23 Oct. 2019.

[14]S. Cruz-Lara et. al, "Topics in Language Resources for Translation and Localization (Chapter: Standardizing the Management and the Representation of Multilingual Data: The Multi-Lingual Information Framework). John Benjamins Publishing Company, 2008.

[15]ISO 24616:2012. Language resources management - Multilingual information framework. https://www.iso.org/standard/37330.html

[16] Une nouvelle gouvernance pour les données au XXle siècle, des standards pour la circulation et la protection des données personnelles, PIMS - Personal Information Management Systems, pp.1221, www.privacytech.fr, 10/04/2019, CC-by-SA

[17]WWF rapport sur l'industrie de l'habillement et des textiles. https://www.wwf.ch/fr/nos-objectifs/wwfrapport-sur-lindustrie-de-Ihabillement-et-des-textiles

[18]Web 3D Consortium. https://www.web3d.org/

[19] Industry Connections (IC) 3D Body Processing. https://standards.ieee.org/industryconnections/3d/bodyprocessing.html 